\title{
Fibrin Degradation Products Measurement
}

National Cancer Institute

\section{Source}

National Cancer Institute. Fibrin Degradation Products Measurement. NCI Thesaurus. Code C82013.

The determination of the amount of fibrin degradation products present in a sample. 